\title{
Arsenic speciation of groundwater and agricultural soils in central Gangetic basin, India
}

\author{
M. Kumar ${ }^{1,2}$ \& AL. Ramanathan ${ }^{2}$ \\ ${ }^{1}$ Department of Environmental Science, School of Earth, Environment \& Space Studies, \\ Central University of Haryana, Jant Pali, Mahendergarh, India \\ ${ }^{2}$ School of Environmental Sciences, Jawaharlal Nehru University, New Delhi, India
}

\begin{abstract}
The current study was performed to estimate the amount of inorganic forms [arsenite, As(III) and arsenate, $\mathrm{As}(\mathrm{V})$ of arsenic (As) present in groundwater $(\mathrm{n}=18)$ and agricultural soils from eleven locations in the central Gangetic basin, India. Water samples were speciated using a disposable cartridge, while a microwave assisted method was used to obtain As species in agricultural soil samples. The estimation of As species concentration was performed using ion chromatography (IC) coupled with inductively coupled plasma mass spectrometer (ICP-MS) in solution matrix. Approximately $73 \%$ of the groundwater samples $(\mathrm{n}=18)$ show $\mathrm{As}(\mathrm{III})$ as the dominant species, while $27 \%$ reveals As(V) was the dominant species. Groundwater $(80 \%)$ samples exceeded the World Health Organization (WHO) guideline value $\left(10 \mu \mathrm{g} \mathrm{L}^{-1}\right)$ of As. The concentration of As(III) in agricultural soil samples varies from not detectable to $40 \mu \mathrm{g} \mathrm{kg}^{-1}$ and As(V) was observed as the major species (ranging from 1050 to $6835 \mu \mathrm{g} \mathrm{kg}^{-1}$ ) while the total As concentration varied from 3528 to $14,690 \mu \mathrm{g} \mathrm{kg}^{-1}$. Arsenate (V) species dominate in oxygen-rich environments and well-drained soils, whereas in the reducing conditions, such as regularly flooded soils, As(III) is the stable oxidation state.
\end{abstract}

\section{INTRODUCTION}

Arsenic (As) is a common element which forms many compounds in the environment and biological system as well. Nowadays, natural occurrence of As has been reported in almost all the region of South East Asia and other countries around the world like; Mexico, Argentina, Poland and Canada (Chen et al., 2006). The determination of the total As concentration alone is insufficient for many environmental exposure scenarios, but the determination of the species is important in order to accurate assessments of environmental impact and human health risk (Rahman et al., 2009; Vassileva et al., 2001), the toxicity and bio-availability of As compounds depend on the chemical form of the As (Gong et al., 2002) and cycling of As in different environmental conditions like lake (Zheng et al., 2003; Kumar et al., 2018). Current study reported As level and speciation in water, agriculture fields soil using ion chromatography (IC) coupled with inductively coupled plasma mass spectrometer (ICP-MS) in solution matrix in Gangetic basin, India.

\section{METHODS}

Water samples (18) were collected from two blocks Mohiuddin Nagar and Mohanpur of the district Samastipur, Bihar during June 2015 to know Asspeciation ratio in reducing environment of central
Gangetic basin. Agricultural soil samples were collected from 11 different locations of the As-affected area. Generally, shallow tubewells water used for irrigation in this area, which is contaminated with geogenic As contamination. A microwave digester (CEM, MARS 6) having 42 digester vessels were used to digest all soil and sediment samples. Microwaveassisted extraction technique (1 M orthophosphoric acid) was used for the extraction of the As species from agricultural soils (Kumar et al., 2016a).

\section{RESULTS AND DISCUSSION}

Arsenic speciation for groundwater are shown in Table 1. Approximately 73\% (14 out of 18 ) of the samples shows As(III) as dominant species while only $27 \%$ (5 out of 18 ) shows $\mathrm{As}(\mathrm{V})$ as dominant species. Arsenite (III) for all samples was $63.8 \%$ and As(V) was $36.2 \%$. It is expected for groundwaters where reducing environment occurs in the aquifers.

Many studies also have been found arsenite as the primary arsenic species present in central Gangetic plain (Kumar et al., 2016b), West Bengal and Bangladesh (Kim et al., 2003). Groundwaters mainly have inorganic As (Elci et al., 2008; Hughes et al., 2011), hence the sum of the two species (AsIII and AsV) will be equal to the total As (Table 1).

To know the level of the As in the agricultural soil which is irrigated by water with As concentration 
Table 1. Groundwater sample As species in central Gangetic basin.

\begin{tabular}{lcrrr}
\hline S. No. & As(III) & As(V) & \multicolumn{1}{c}{ As(t) } & As(III)/As(V) \\
\hline 1 & 57.8 & 42.19 & 29.44 & 1.37 \\
2 & 95.8 & 4.16 & 81.42 & 23.02 \\
3 & 44.9 & 55.09 & 35.14 & 0.82 \\
4 & 84.6 & 15.38 & 5.98 & 5.50 \\
5 & 91.8 & 8.23 & 12.64 & 11.15 \\
6 & 76.7 & 23.29 & 1.47 & 3.29 \\
7 & 88.1 & 11.94 & 2.62 & 7.38 \\
8 & 8.1 & 91.90 & 5.59 & 0.09 \\
9 & 67.6 & 32.39 & 14.82 & 2.09 \\
10 & 70.9 & 29.11 & 19.20 & 2.43 \\
11 & 57.7 & 42.29 & 1.35 & 1.36 \\
12 & 87.5 & 12.46 & 2.79 & 7.03 \\
13 & 42.9 & 57.09 & 16.66 & 0.75 \\
14 & 58.9 & 41.06 & 6.95 & 1.44 \\
15 & 94.6 & 5.43 & 1.34 & 17.41 \\
16 & 14.78 & 85.23 & 2.65 & 0.17 \\
17 & 11.6 & 88.40 & 23.50 & 0.13 \\
18 & 79.6 & 20.38 & 104.7 & 3.91 \\
\hline
\end{tabular}

$\mathrm{As}(\mathrm{III})$ and $\mathrm{As}(\mathrm{V})$ represented in (\%) and $\mathrm{As}($ total) presented in $\mu \mathrm{g} \mathrm{L}^{-1}$.

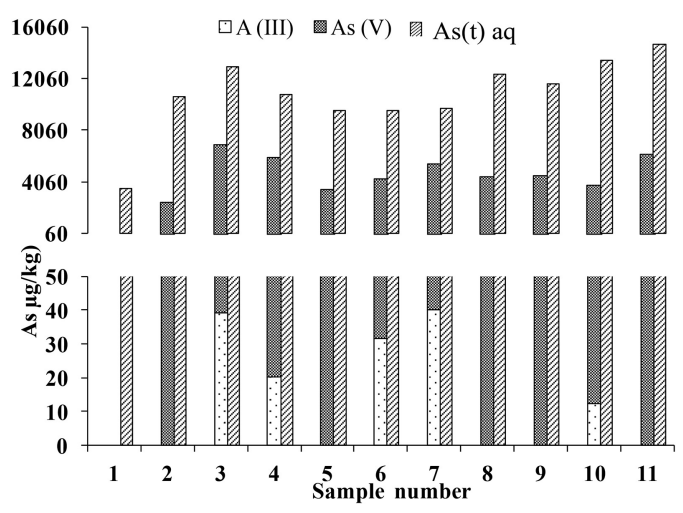

Figure 1. As speciation in agricultural soil samples of central Gangetic basin.

levels of $>10 \mu \mathrm{g} \mathrm{L}^{-1}$. Tubewell water was not collected from the corresponding agricultural soil samples. The total concentration of As observed in agricultural soils ranged from $3527-14690 \mu \mathrm{g} \mathrm{kg}^{-1}$ with the percent extractable concentration of 22.8 to $55.9 \mu \mathrm{g} \mathrm{kg}^{-1}$ (Fig. 1). The concentration of As(III) and $\mathrm{As}(\mathrm{V})$ varied from bdl- $40.07 \mu \mathrm{g} \mathrm{kg}^{-1}$ and 1050 $6835 \mu \mathrm{g} \mathrm{kg}^{-1}$ respectively. $\mathrm{As}(\mathrm{V})$ was detected in almost all the agricultural soil samples, while As(III) was detected only in 6 samples having a lower range of $\left(0.1-40 \mathrm{mg} \mathrm{kg}^{-1}\right)$ only. Arsenate [As(V)] species dominated in oxygen-rich environments and well-drained soils, whereas in the reducing conditions, such as regularly flooded soils, arsenite [As(III)] is the stable oxidation state, but elemental As and arsine can also be present in strongly reducing environments (Vicky-Singh et al., 2010).

\section{CONCLUSIONS}

The study revealed that As(III) dominated in groundwater, while $\mathrm{As}(\mathrm{V})$ in the agricultural filed soil. The dominance of As(III) indicates the reducing conditions of the aquifers in the central Gangetic basin. Groundwater $(80 \%)$ samples exceeded the World Health Organization (WHO) guideline value $\left(10 \mu \mathrm{g} \mathrm{L}^{-1}\right)$ of As. The concentration of As(III) in agricultural soil samples was comparatively very low, while $\mathrm{As}(\mathrm{V})$ was observed as the dominating species. It was also observed that $\mathrm{As}(\mathrm{V})$ species dominated in oxygen-rich environments and well-drained soils, whereas As(III) dominated in the regularly flooded locations.

\section{REFERENCES}

Chen, Z., Akter, K.F., Rahman, M.M. \& Naidu, R. 2006. Speciation of arsenic by ion chromatography inductively coupled plasma mass spectrometry using ammonium eluents. J. Sep. Sci. 29: 2671-2676.

Elci, L., Divrikli, U. \& Soylak, M. 2008. Inorganic arsenic speciation in various water samples with GFAAS using coprecipitation. Int. J. Environ. Anal. Chem. 88: 711-723.

Gong, Z., Lu, X., Ma, M., Watt, C. \& Le, X.C. 2002. Arsenic speciation analysis. Talanta 58:77-96.

Hughes, M.F., Beck, B.D., Chen, Y., Lewis, A.S. \& Thomas, D.J. 2011. Arsenic exposure and toxicology: a historical perspective. Toxicol. Sci. 123:305-332.

Kim, M.J., Nriagu, J. \& Haack, S. 2003. Arsenic behavior in newly drilled wells. Chemosphere 52: 623-633.

Kumar, M., Ramanathan, AL., Rahman, M.M. \& Naidu, R. 2016a. Concentrations of inorganic arsenic in groundwater, agricultural soils and subsurface sediments from the middle Gangetic plain of Bihar, India. Sci. Total Environ. 573, 1103-1114.

Kumar, M., Rahman, M.M., Ramanathan, A.L. \& Naidu, R. 2016b. Arsenic and other elements in drinking water and dietary components from the middle Gangetic plain of Bihar, India: health risk index. Sci. Total Environ. 539: 125-134.

Kumar, M. \& Ramanathan, A.L. 2018. Vertical Geochemical Variations and Speciation Studies of As, Fe, Mn, Zn, and $\mathrm{Cu}$ in the Sediments of the Central Gangetic Basin: Sequential Extraction and Statistical Approach. Int. J. Environ. Res. Publ. Health 15(2): 183.

Rahman, M.M., Chen, Z. \& Naidu, R. 2009. Extraction of arsenic species in soils using microwave-assisted extraction detected by ion chromatography coupled to inductively coupled plasma mass spectrometry, Environ. Geochem. Hlth. 31: 93-102.

Vassileva, E., Becker, A. \& Broekaert, J. 2001. Determination of arsenic and selenium species in groundwater and soil extracts by ion chromatography coupled to inductively coupled plasma mass spectrometry. Anal. Chim. Acta 441: 135-146.

Vicky-Singh, Brar, M.S., Preeti-Sharma \& Malhi, S.S. 2010. Arsenic in Water, Soil, and Rice Plants in the IndoGangetic Plains of Northwestern India. Commun. Soil Sci. Plant Anal. 41: 1350-1360.

Zheng, J., Hintelmann, H., Dimock, B. \& Dzurko, M.S. 2003. Speciation of arsenic in water, sediment, and plants of the Moira watershed, Canada, using HPLC coupled to high resolution ICP-MS. Anal. Bioanal. Chem. 377: 14-24. 